\title{
POTENTIAL ANTI-INFLAMMATORY ACTIVITY OF PLUMBAGO ZEYLANICA
}

\author{
VETRISELVAN SUBRAMANIYAN ${ }^{1}$, VELMURUGAN PARAMASIVAM ${ }^{2}$
}

${ }^{1}$ Department of Pharmacology, Faculty of Medicine, MAHSA University, Kuala Lumpur, Malaysia. ${ }^{2}$ Department of Biotechnology, SRM University, Chennai, Tamil Nadu, India. Email: vetricology@gmail.com

Received: 01 June 2017, Revised and Accepted: 15 August 2017

ABSTRACT

Objective: To determine the anti-inflammatory activity of dichloromethane extract of Plumbago zeylanica (DMEPZ), and its possible mechanism of action.

Methods: Male Wistar rats (180-200 g) under controlled standard conditions $\left(24 \pm 1^{\circ} \mathrm{C}, 55-58\right.$ humidity and 12 hrs light/dark cycle). The groups were divided into 5 groups (n=6/group) and assigned as positive control, negative control, and standard and two different test dose groups of $P$. zeylanica. Paw edema induced by subplantar injection of $0.1 \mathrm{~mL}$ of carrageenan (suspended in $1 \%$ carboxymethyl cellulose) into the right hind paw in all groups except negative control group. Granuloma induced by cotton pellets $(10 \pm 1 \mathrm{mg}$ ) were implanted into groin region of each rat. The groups were divided into 4 groups ( $n=6 /$ group) and assigned as possitive control, two different test dose groups of $P$. zeylanica and standard.

Results: Oral administration of DMEPZ shown a significant $(\mathrm{p}<0.05)$ dose-dependent protection against carrageenan-induced paw edema. At $1^{\text {st }}$ hr, P. zeylanica shown an inhibition effect of edema in the different doses of $250 \mathrm{mg} / \mathrm{kg}$ and $500 \mathrm{mg} / \mathrm{kg}$ were found to be 28.57 and $31.79 \%$, respectively. At $3^{\text {rd }} \mathrm{hrs}$, the paw edema inhibition was found to be 30.70 and $40.15 \%$, respectively. Diclofenac $(25 \mathrm{mg} / \mathrm{kg}$ ) had effect of 34.10 and $41.73 \%$ (p<0.001) inhibition of paw edema at in 1 and 3 hrs. P. zeylanica $500 \mathrm{mg} / \mathrm{kg}$ showed percentage inhibition of wet and dry cotton pellet granuloma in rats $55.84 \%$ and $47.92 \%$, respectively.

Conclusion: Thus, the present study revealed that the DMEPZ offered significant protection against inflammation.

Keywords: Plumbago zeylanica, Inflammation, Anti-inflammatory, Anti-granuloma activity.

(C) 2017 The Authors. Published by Innovare Academic Sciences Pvt Ltd. This is an open access article under the CC BY license (http://creativecommons. org/licenses/by/4. 0/) DOI: http://dx.doi.org/10.22159/ajpcr.2017.v10i11.20357

\section{INTRODUCTION}

Plumbago zeylanica is a family of Plumbaginaceae and commonly known as "chittiramulam or vellai" in Tamil and widely distributed in southern parts of India. In the traditional system of medicine, different parts of the plant used a variety of diseases [1,2]. P. zeylanica is widely used as a gastrointestinal disease [3], respiratory disease [4], gonorrhea and syphilis [5], inflammatory diseases [6], scabies [7], blood coagulation profile activity [8], antiallergic activity [1], central nervous system (CNS) stimulant activity [9], antioxidant [10], antiinfertility activity [11], lipid metabolism activity [12], and cytotoxicity activity [13]. There is no documentary evidence of contraindication and interaction. Subcutaneous injection of the carrageenan is to promote hyperalgesia and to develop erythema. This response due to proinflammatory mediators such as bradykinin, histamine, tachykinins, reactive oxygen, and nitrogen species [14]. These mediators readily migrate to sites of inflammation and proven with current study. After administration of the carrageenan showed significant inflammatory response in paw edema model [15]. Inflammation is a disorder involving swelling associated with multiple complex mediators [16]. Inflammation is a pathological state and characterized by concurrent active inflammation, tissue destruction, and attempts at repairing stage [17]. The natural system of medicines is believed that one of the important source of health-care field [18]. However, we investigated the protective effect of dichloromethane extract of P. zeylanica (DMEPZ) influence on regulating complex mediators in inflammatory rats to provide a definite experimental basis for the clinical medication.

\section{METHODS}

Preparation of the extracts

The roots of $P$. zeylanica were collected in Nellore District, India. Botanical identification and voucher specimen No. RIP/2013/120 has been deposited in the museum of the Department of Pharmacognosy at Ratnam Institute of Pharmacy, Nellore, India. The roots were dried under shade, segregated, and pulverized by a mechanical grinder and passed through a 40 mesh sieve. The powdered $1 \mathrm{~kg}$ of the material was soaked in solvent dichloromethane $(4000 \mathrm{~mL})$ for $48 \mathrm{hrs}$ and repeats the process for thrice to get complete extraction. The solvent was removed in a rotary vacuum and stored in an airtight container.

\section{Drugs and chemicals}

Carrageenan was obtained from SD. Fine Chemicals Limited, Bombay. All other chemicals were of analytical grade procured from reputed Indian manufacturers.

\section{Experimental animals}

The experimental design was approved by the Institutional ethical committee of Ratnam Institute of Pharmacy, Nellore (Ethical Approval No. 13/(Institutional Animal Ethics Committee/Pharma/RIP/2013). Male albino Wistar rats weighing 180-200 g (6-8 weeks) were supplied from animal facility and housed six animals per cage at $23-25^{\circ} \mathrm{C}$ and relative humidity between 55 and $58 \%$, respectively. They had access to food and water ad libitum and were exposed to alternate $12 \mathrm{hrs} \mathrm{light}$ and dark cycles.

\section{Acute toxicity study}

The acute toxicity study was carried out albino Wistar rats. The experiment made into six groups containing six animals in each group. DMEPZ was suspended in critical micelle concentration + dimethyl-sulfoxide and starting dose from 5, 50, 100, 200, and 400 to $2000 \mathrm{mg} / \mathrm{kg}$ body weight (b.w) to all groups, respectively. These animals were observed for a 72 hrs period. The number of deaths was expressed as a percentile and the lethal dose 50 (LD50) was determined by probit a test using the death percentage versus the log dose [19]. 
The time at which signs of toxicity appear and disappear was observed systematically and recorded for each animal.

\section{Carrageenan-induced rat paw oedema}

A total of 30 animals were equally divided into 5 groups of six each. Before the experimental study allowed for overnight fasting in the rats. All the groups of rats, hind paw volume measured by the plethysmograph instrument (Yukui et al.,). All the groups were injected $0.1 \mathrm{~mL}$ of a suspension of $1 \%$ carrageenan under the subplantar aponeurosis of the right hind paw of rats except Group I. Group I is the positive control and injected $0.1 \mathrm{~mL}$ saline. Group II is a negative control and injected $0.1 \mathrm{~mL}$ of a suspension of $1 \%$ carrageenan under the subplantar region. Group V served as positive control and received diclofenac sodium was injected intraperitoneally at $25 \mathrm{mg} / \mathrm{kg}$ b.w $1 \mathrm{~h}$ before carrageenan injection. Group III and IV were orally administered with DMEPZ 250, $500 \mathrm{mg} / \mathrm{kg}$ b.w, respectively. After carrageenan injection, paw volume was measured at 1,2 , and 3 hrs to determine the inflammatory activity.

In the rats, percentage of inhibition of edema calculated using the following formula,

$\%$ of inhibition of oedema=Vc-Vt/Vc $\times 100$

Where, Vc is the edema in the disease control group and Vt is the edema in the treatment group.

\section{Cotton pellet-induced granuloma}

A total of 24 were equally divided into four groups of six each. The sterile cotton pellets in milligram of $10 \pm 1$ were implanted to subcutaneously into both sides of the groin region of each rat, and before the pellets implantation rats were anesthetized. Group I received the vehicle $(0.9 \% \mathrm{NaCl}, 10 \mathrm{~mL} / \mathrm{kg} \mathrm{b.w})$ and served as control. The dose of 250 and $500 \mathrm{mg} / \mathrm{kg}$ b.w of DMEPZ was orally administered as Group II and III rats for seven consecutive days from the first day of cotton pellet implantation. Diclofenac at a dose of $25 \mathrm{mg} / \mathrm{kg}$ b.w received group IV

Table 1: HPLC profiles of the DMEPZ

\begin{tabular}{lllll}
\hline $\begin{array}{l}\text { Retention } \\
\text { time }\end{array}$ & Area (mV.s) & Height (mV) & Area (\%) & Height (\%) \\
\hline 3.580 & 46.3701 & 2.7367 & 0.3227 & 0.3232 \\
4.860 & 121.0003 & 3.9909 & 0.8420 & 0.4714 \\
6.713 & 91.5804 & 5.8665 & 0.6373 & 0.6929 \\
7.447 & 419.5180 & 22.7855 & 2.9192 & 2.6913 \\
8.233 & 137.2056 & 13.0742 & 0.9547 & 1.5443 \\
8.880 & 4067.7216 & 316.7515 & 28.3048 & 37.4133 \\
10.147 & 21.8959 & 1.5991 & 0.1524 & 0.1889 \\
10.867 & 11.8915 & 0.8879 & 0.0827 & 0.1049 \\
13.247 & 54.9761 & 3.3796 & 0.3825 & 0.3992 \\
14.400 & 44.8306 & 2.3031 & 0.3119 & 0.2720 \\
15.180 & 8925.8227 & 461.7467 & 62.1094 & 54.5395 \\
24.833 & 128.1171 & 3.6027 & 0.8915 & 0.4255 \\
27.660 & 195.0064 & 5.6933 & 1.3569 & 0.6725 \\
38.853 & 105.1888 & 2.2108 & 0.7320 & 0.2611 \\
\hline
\end{tabular}

Values are expressed as mean \pm SE $(n=6)$. Data were analyzed using one-way analysis of variance followed by Dunnett's multiple comparison test.

SE: Standard error, P. zeylanica: Plumbago zeylanica, HPLC: High-performance liquid chromatography animals. Rats were anesthetized on the $8^{\text {th }}$ day and pellets with the granuloma tissues carefully removed and made free from extraneous tissues. The wet pellets dried an oven at $60^{\circ} \mathrm{C}$ for $24 \mathrm{hrs}$. Before and after dry cotton pellets were weighed. This assessment was to determine the granuloma formation in rats. DMEPZ effect was compared with control and standard drug-treated animals.

\section{Statistical analysis}

All the data were expressed as means \pm standard error mean. The measurement data of multiple groups were compared with one-way ANOVA, the comparison between normal control versus other groups, and a value of $\mathrm{p}<0.05$ was considered significant.

\section{RESULTS}

\section{Acute toxicity test}

There are no significant physiological, behavioral, and biochemical alterations at different dose group of DMEPZ-treated rats. These effects revealed extract was safety as non-toxic and no mortality in rats. The median LD50 was determined highest dose tested, i.e., $2000 \mathrm{mg} / \mathrm{kg}$ b.w. Hence, $P$. zeylanica at doses of 250 and $500 \mathrm{mg} / \mathrm{kg}$, p.o. was selected for further pharmacological study.

\section{Instrumental analysis}

DMEPZ was subjected to high-performance liquid chromatography (HPLC). The result obtained by gradient chromatography on C-18 column with U.V. detection at $254 \mathrm{~nm}$ and eluted with 70:30:1 (Methanol:Water:Acetic acid). There was retention time in crude extract content for the 14 different samples as shown in Table 1.

\section{Carrageenan-induced rat paw oedema}

DMEPZ against the inflammatory effect in significant $(\mathrm{p}<0.001)$ at the different dose groups such as 250 and $500 \mathrm{mg} / \mathrm{kg}$ b.w (Fig. 1). These results were comparable to reference drug of diclofenac, the doses 250 and $500 \mathrm{mg} / \mathrm{kg}$ b.w in 3 hrs inhibited 31.79 and $40.15 \%$, respectively, in carrageenan-induced rat paw oedema.

\section{Cotton pellets-induced granuloma}

Decreased level of granuloma reflected in DMEPZ-treated groups as shown in Table 2. As the results dose group of 250 and $500 \mathrm{mg} / \mathrm{kg}$ b.w weight of the cotton pellets was significantly reduced. Moreover, the anti-inflammatory effect of DMEPZ slightly less than diclofenac but statistically significant.

\section{DISCUSSION}

Acute toxicity studies of P. zeylanica up to $2000 \mathrm{mg} / \mathrm{kg}$ were found to be non-toxic and did not cause any death of the tested animals. Previous data indicated that polyphenolic compounds may protect against oxidative damage and have anti-inflammatory activity [18]. Tilak et al. study reported plumbagin one of the major constituent of $P$. zeylanica to protect oxidative stress [20]. As Fig. 2 showed that HPLC analysis showed that retention time in crude extract content for the 14 different samples (Table 1). There are several mediators involved in inflammation including histamine, serotonin, and bradykinin. In the late phase to produce the inflammation through increased vascular permeability. Inflammation in local or systemic to assess with levels of pro-inflammatory cytokines tumor necrosis factor $-\alpha$, interleukin

Table 2: Effect of DMEPZ on cotton pellets-induced granuloma in rats

\begin{tabular}{lllll}
\hline Treatment & Dose (mg/kg) & $\begin{array}{l}\text { Weight of wet cotton } \\
\text { pellets } \mathbf{( m g )}\end{array}$ & Percentage inhibition & $\begin{array}{l}\text { Weight of dry cotton } \\
\text { pellets (mg) }\end{array}$ \\
\hline Control & Saline $2 \mathrm{~mL}$ & $182.34 \pm 1.44$ & $48.33 \pm 0.79$ \\
DMEPZ & 250 & $106.40 \pm 1.97^{\mathrm{a}}$ & 41.64 & $33.66 \pm 0.62^{\mathrm{a}}$ \\
DMEPZ & 500 & $80.52 \pm 1.62^{\mathrm{a}}$ & 55.84 & $25.17 \pm 0.62^{\mathrm{a}}$ \\
Diclofenac & 25 & $77.59 \pm 1.10^{\mathrm{a}}$ & 57.44 & $23.54 \pm 0.58^{\mathrm{a}}$ \\
\hline
\end{tabular}

Values are expressed as mean $\pm \mathrm{SE}(\mathrm{n}=6)$. Data were analyzed using one-way analysis of variance followed by Dunnett's multiple comparison test. ${ }^{\mathrm{a}} \mathrm{p}<0.001 ; \mathrm{p}<0.05$ considered as significant; NS: Non-significant; All groups are compared with normal control. SE: Standard error, DMEPZ: Dichloromethane extract of Plumbago zeylanica 


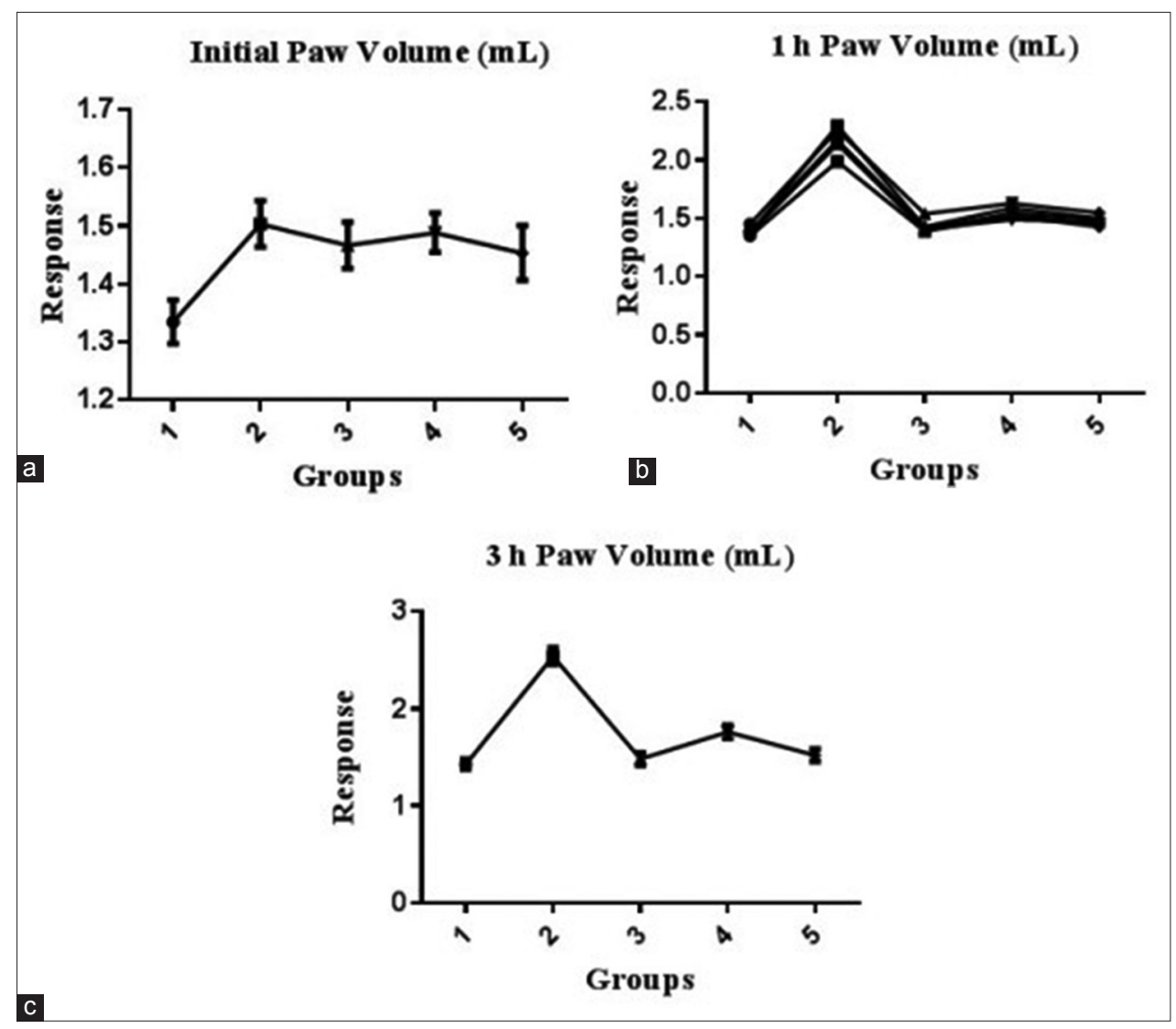

Fig. 1: (a) Effect of dichloromethane extract of Plumbago zeylanica (DMEPZ) on carrageenan-induced rat (b) effect of DMEPZ on carrageenan-induced paw edema (basal time) rat paw edema (after $1 \mathrm{hr}$ ) (c) effect of DMEPZ on carrageenan-induced rat paw edema (after $3 \mathrm{hrs}$ )

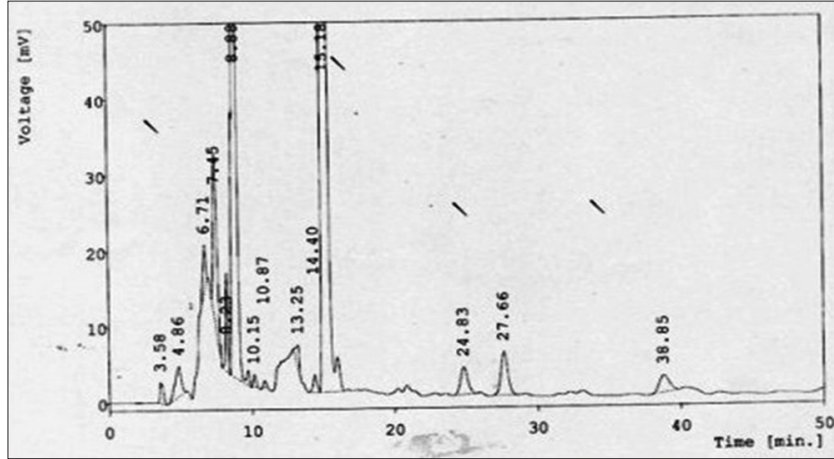

Fig. 2: High-performance liquid chromatography profiles of the dichloromethane extract of Plumbago zeylanica

IL - 6, and IL - 1 [21]. Non-steroidal anti-inflammatory drug including indomethacin or aspirin is not inhibiting initial phase of edema and has been attributed to the release of chemical mediators. The second phase of swelling attributed to the production of cyclooxygenase -2 in the hind paw as revealed in previous study [22]. In the recent years, the biological effect of phytosterols emphasis on their in vitro and in vivo immune modulatory activity [23].

Some of the chemotactic and chemokinetic agents reported to be involved topical inflammation through arachidonic acid by lipoxygenase activity such as 12-hydroxy-6,8,11,14-eicosatetraenoic acid from platelets, leukotriene B4 from polymorphonuclear leukocytes, and 5-hydroxy-6,8,11,14-eicosatetraenoic acid [24]. Carrageenan-induced edema has been commonly used as an experimental animal model for acute inflammation. In the carrageenan-induced rat paw edema model, except control group, and all examined with DMEPZ administered orally. The results showed significant anti-inflammatory activity, where dose $500 \mathrm{mg} / \mathrm{kg}$ exhibited the highest effect. Initially, 1-2 h, carrageenan mainly mediated by histamine, serotonin, and increased synthesis of prostaglandins in the damaged tissue surroundings [25]. After sustained by prostaglandin release and mediated by bradykinin, leukotrienes, and polymorphonuclear cells [26]. The findings of the present study confirmed carrageenan causes the production and release of nitric oxide (NO) at the injured site NO, which alerts pathological conditions of NO synthesis, this could be involved in tissue injury, including edema and hyperalgesia condition [27].

Treatment with P. zeylanica extract showed significant action against paw edema in a dose-dependent manner. At $500 \mathrm{mg} / \mathrm{kg}$ dose of DMEPZ was quite comparable to diclofenac $(25 \mathrm{mg} / \mathrm{kg})$. The present study results indicate that a dose of 250 and $500 \mathrm{mg} / \mathrm{kg}$ b.w influencing against the inflammatory process. The inflammation due to arachidonic cofactors also revealed a previous study [28]. Among groups, cotton pellet granuloma tissue compared with wet and dry weight of the cotton pellets. Different dose of 250 and $500 \mathrm{mg} / \mathrm{kg}$ b.w of DMEPZ showed curing effect of inflammation comparable to diclofenac treatment. The results demonstrated that herbal medicine has ability to treat inflammatory diseases. Hence, it needs further detailed pharmacological and clinical investigations to prove it as an effective therapeutic agent for inflammation.

\section{CONCLUSION}

P. zeylanica extract showed active against carrageenan-induced rat paw edema in a dose-dependent manner. At $500 \mathrm{mg} / \mathrm{kg}$ P. zeylanica was comparable to diclofenac $(25 \mathrm{mg} / \mathrm{kg})$ in the inhibition of paw edema. The effect of DMEPZ may be attributed to its free radical scavenger activity and protection of apoptosis. In the experimental models, DMEPZ was found to exhibit significant $(\mathrm{p}<0.001)$ anti-inflammatory activity, 
and the results were comparable to standard drug of diclofenac. Thus, the present study revealed DMEPZ phytoconstituents exerts the desired effects against hypersensitivity and inflammation.

\section{ACKNOWLEDGMENTS}

Authors are thanking to Department of Pharmacology, Ratnam Institute of Pharmacy, India for providing necessary facilities for carrying out research work.

\section{REFERENCES}

1. Tabassum N, Hamdani M. Plants used to treat skin diseases. Pharmacogn Rev 2014;8(15):52-60.

2. Shankar R, Lavekar GS, Deb S, Sharma BK. Traditional healing practice and folk medicines used by Mishing community of North East India. J Ayurveda Integr Med 2012;3(3):124-9.

3. Maurya SK, Seth A, Laloo D, Singh NK, Gautam DN, Singh AK. Sodhana: An Ayurvedic process for detoxification and modification of therapeutic activities of poisonous medicinal plants. Anc Sci Life 2015;34(4):188-97.

4. Kumar D, Ganguly K, Hegde HV, Patil PA, Roy S, Kholkute SD. Activity of Plumbago zeylanica Linn. Root and Holoptelea integrifolia Roxb. Bark pastes in acute and chronic paw inflammation in Wistar rat. J Ayurveda Integr Med 2014;5:33-7.

5. Kishore N, Mishra BB, Tiwari KV, Tripathi V. An account of phytochemicals from Plumbago zeylanica (Family: Plumbaginaceae): A natural gift to human being. Chron Young Sci 2012;3:178-98.

6. Parekar RR, Bolegave SS, Marathe PA, Rege NN. Experimental evaluation of analgesic, anti-inflammatory and anti-platelet potential of Dashamoola. J Ayurveda Integr Med 2015;6(1):11-8.

7. Ariyanathan S, Saraswathy A, Rajamanickam GV. Quality control standards for the roots of three plumbago species. Indian J Pharm Sci 2010;72(1):86-91

8. Shukla P, Singh RK. Toxicogenomics of phenylhydrazine induced hematotoxicity and its attenuation by plumbagin from Plumbago zeylanica. Pharmacogn Mag 2015;11 Suppl 3:S380-7.

9. Ittiyavirah SP, Ruby R. Effect of hydro-alcoholic root extract of Plumbago zeylanica 1 alone and its combination with aqueous leaf extract of Camellia sinensis on haloperidol induced Parkinsonism in Wistar rats. Ann Neurosci 2014;21(2):47-50.

10. Dai Y, Hou LF, Chan YP, Cheng L, But PP. Inhibition of immediate allergic reactions by ethanol extract from Plumbago zeylanica stems. Biol Pharm Bull 2004;27(3):429-32.

11. Bopaiah CP, Pradhan N. Central nervous system stimulatory action from the root extract of Plumbago zeylanica in rats. Phytother Res 2001;15(2):153-6.

12. Jain P, Sharma HP, BasriF, BaraikB, KumariS, PathakC.Pharmacological profiles of ethno-medicinal plant: Plumbago zevlanica 1 . A review. Int J Pharm Sci Rev Res 2014;24:157-63.

13. Kumar D, Patil PA, Roy S, Kholkute SD, Hegde HV, Nair V. Comparative toxicity profiles of Plumbago zeylanica L. Root petroleum ether, acetone and hydroalcoholic extracts in Wistar rats. Ayu 2015;36:329-34.

14. Zholos AV. TRP channels in respiratory pathophysiology: The role of oxidative, chemical irritant and temperature stimuli. Curr Neuropharmacol 2015;13(2):279-91

15. Ma Y, Li Y, Li X, Wu Y. Anti-inflammatory effects of 4-methylcyclopentadecanone on edema models in mice. Int J Mol Sci 2013;14(12):23980-92.

16. Ricciotti E, Fitzgerald AG. Prostaglandins and Inflammation. Arterioscler Thromb Vasc Biol 2011;31:986-1000.

17. Wilgus TA, Roy S, McDaniel JC. Neutrophils and wound repair: Positive actions and negative reactions. Adv Wound Care (New Rochelle) 2013;2(7):379-88.

18. Ameni D, Baghiani A, Boumerfeg S, Dahamna S, Khennouf S, Abu Zarga $\mathrm{MH}$, et al. Phytochemical profiles, antioxidant capacity and protective effect against AAPH-induced mouse erythrocyte damage by Daphne Gnidium L. Shoots extracts. Int J Pharm Pharm Sci 2015;11:148-56.

19. Raj J, Chandra M, Dogra TD, Pahuja M, Raina A. Determination of median lethal dose of combination of endosulfan and cypermethrin in wistar rat. Toxicol Int 2013;20(1):1-5.

20. Tilak JC, Adhikari S, Devasagayam TP. Antioxidant properties of Plumbago zeylanica, an Indian medicinal plant and its active ingredient, plumbagin. Redox Rep 2004;9(4):219-27.

21. Noh MK, Jung M, Kim SH, Lee SR, Park KH, Kim DH, et al. Assessment of IL-6, IL-8 and TNF-a levels in the gingival tissue of patients with periodontitis. Exp Ther Med 2013;6(1):847-51.

22. Chattopadhyay P, Hazarika S, Dhiman S, Upadhyay A, Pandey A, Karmakar S, et al. Vitex negundo inhibits cyclooxygenase-2 inflammatory cytokine-mediated inflammation on carrageenan-induced rat hind paw edema. Pharmacognosy Res 2012;4(3):134-7.

23. Haj Said AA, El Otmani IS, Derfoufi S, Moussa AB. Highlights on nutritional and therapeutic value of stinging nettle (Urtica dioica). Int J Pharm Pharm Sci 2015;7:8-14.

24. Viljoen A, Mncwangi N, Vermaak I. Anti-inflammatory iridoids of botanical origin. Curr Med Chem 2012;19(14):2104-27.

25. Nesa L, Munira S, Mollika S, Islam M, Choin H, Chouduri AU, et al. Evaluation of analgesic, anti-inflammatory and CNS depressant activities of methanolic extract of Lawsonia inermis barks in mice. Avicenna J Phytomed 2014;4(4):287-96.

26. Khatun H, Majumder R, Al Mamun, Alam EK, Jami SI, Alam B. Preliminary pharmacological activity of the methanolic extract of Premna integrifolia barks in rats. Avicenna J Phytomed 2014;4(3):215-24.

27. Schomberg D, Ahmed M, Miranpuri G, Olson J, Resnick DK. Neuropathic pain: Role of inflammation, immune response, and ion channel activity in central injury mechanisms. Ann Neurosci 2012;19(3):125-32.

28. Gupta M, Mazumder UK, Gomathi P, Selvan VT. Antiinflammatory evaluation of leaves of Plumeria acuminata. BMC Complement Altern Med 2006;6:36. 